\title{
Hemoptysis caused by an endobronchial lipoma
}

Pier Luigi Filosso, MD, Roberto Giobbe, MD, Claudio Mossetti, MD, Enrico Ruffini, MD, and Alberto Oliaro, MD, Torino, Italy

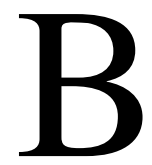

enign tumors of the lung and endobronchial tree are uncommon and need to be differentiated from malignant lesions. Among benign lesions, endobronchial lipoma (EL) is extremely uncommon, accounting for only $0.1 \%$ to $0.5 \%$ of all bronchial tumors. We present a case in which an EL caused hemoptysis, bronchial obstruction, and distal pulmonary fibrosis. Surgical resection with a right lower lobectomy was accomplished.

\section{Clinical Summary}

A 62-year-old man who smoked heavily had hemoptysis sporadically for 3 years. Six months before admission he had cough and shortness of breath, which was treated as asthma. Finally, he was admitted to our department because of increasing hemoptysis with fever and purulent secretions.

A chest radiograph demonstrated a right lower pulmonary infiltrate. Thoracic computed tomographic scan showed damage to the right lower lobe and a fat density mass in the right lower bronchus (Figure 1). A bronchoscopic study confirmed a smooth round polypoid endobronchial lesion in the right lower bronchus (Figure 2); histologic and cytolologic studies (biopsy and brushing) found no neoplastic cells. Bronchoscopic resection was not considered feasible because it was impossible to clearly identify the tumor's endobronchial origin. A right thoracotomy was thus performed.

At bronchotomy, a yellow smooth fatty lesion occluding the lower bronchus was found and a frozen section confirmed no neoplastic tissue. Pus was found in the distal pulmonary parenchyma and lobectomy was necessary. A less extensive resection was at risk for postoperative severe infective complications.

Pathologic examination showed mature adipose tissue growing in the submucosal layer, completely covered with ciliate respiratory epithelium. A diagnosis of endobronchial lipoma was made. The resected lung tissue showed important inflammatory infiltrates, pus, and fibrotic areas.

The postoperative course was characterized by fever and purulent bronchial secretions for 6 days, controlled with broad-spectrum antibiothics.

\footnotetext{
From the University of Torino Italy, Department of Thoracic Surgery, Torino, Italy.

Received for publication Aug 31, 2006; revisions received Oct 7, 2007; accepted for publication Oct 19, 2007.

Address for reprints: Pier Luigi Filosso, MD, University of Torino Italy, San Giovanni Battista Hospital, Department of Thoracic Surgery, Via Genova, 3 , 10126 Torino, Italy (E-mail: pierluigifilosso@tiscali.it).

J Thorac Cardiovasc Surg 2008;135:954-5

$0022-5223 / \$ 34.00$

Copyright (C) 2008 by The American Association for Thoracic Surgery doi:10.1016/j.jtcvs.2007.10.049
}

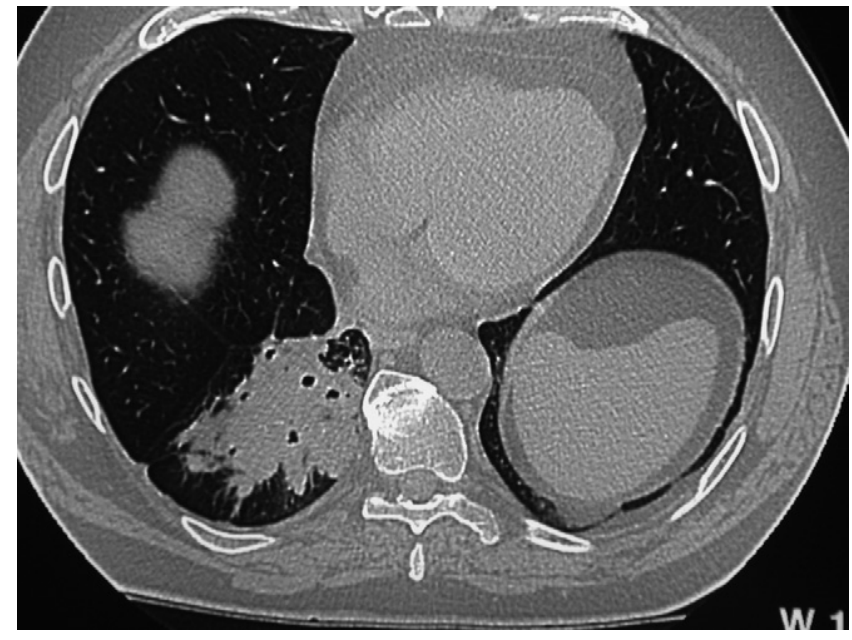

Figure 1. Thoracic computed tomographic scan (particular) with a right lower endobronchial lesion.

\section{Discussion}

We present an uncommon case of EL in which surgical resection of the tumor was accomplished with a right lower lobectomy because of the pulmonary damage following long-term obstructive pneumonia.

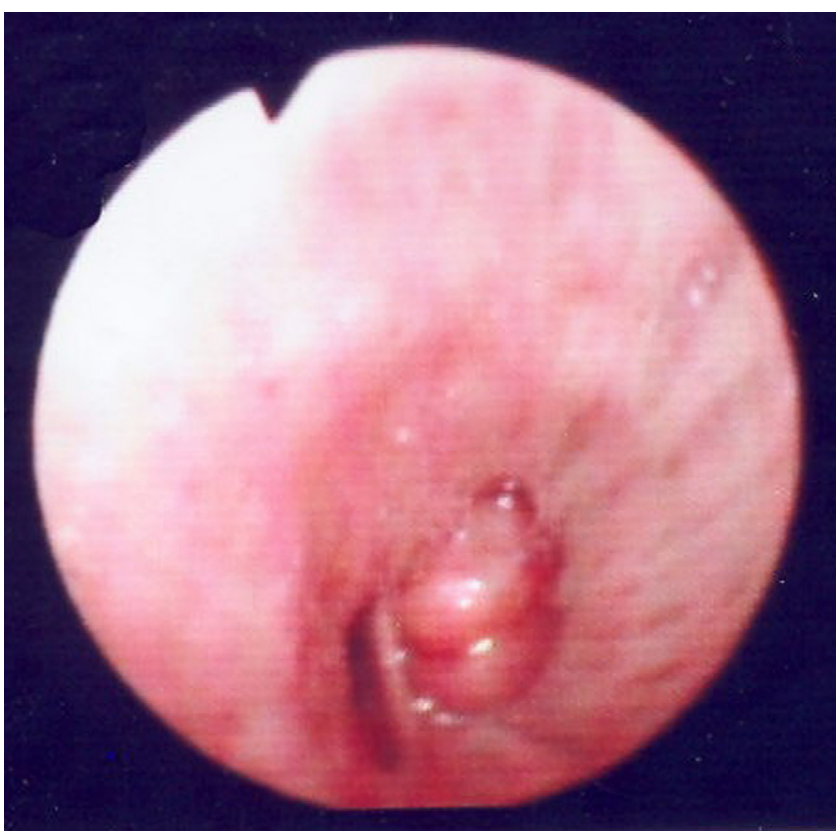

Figure 2. Bronchoscopic view of the lesion. 
ELs are rare benign tumors of the bronchial tree; only 80 cases have been previously reported in the English literature. Most ELs arise in the submucosal layer of the bronchus; fatty tissue is normally found in both the mucosa and the tissue external to the cartilage. Almost two thirds of the tumors occur in the right side, and they are usually located in the main-stem or lobar bronchi. ${ }^{1-3}$ Smoking and obesity are significant risk factors for EL development. ${ }^{4}$ Cough, hemoptysis, and shortness of breath are common symptoms, ${ }^{4,5}$ and patients are often misdiagnosed and treated for asthma for many years, as was our patient.

Owing to the endobronchial tumor growth, irreversible changes in distal pulmonary parenchyma often occur: atelectasis, overinfection, pneumonia, and fibrosis are frequently observed. Bronchoscopy is necessary to identify and locate the lesion and to differentiate it from a malignant tumor. Differential pathologic diagnosis between bronchial carcinoid and lipoma is often difficult because of the paucity of tissue sampling at biopsy. The tumor's surface is usually paler in the lipoma and more friable in the carcinoid. EL sometimes coexists with lung cancer, especially in patients who have smoked heavily. ${ }^{1}$

Bronchoscopic resection should be considered the first choice of treatment for EL; Muraoka and associates ${ }^{2}$ report that no patient presented with bronchial tumor recurrence after EL bronchoscopic resection. Tumor surgical resection is preferred in some cases: (1) extrabronchial growth or subpleural lipomatous disease; (2) expected technical difficulties during the bronchoscopic resection; (3) possible malignant tumor coexisting with EL; and (4) peripheral irreversible lung parenchyma changes after long-term atelectasis or pneumonia.

In conclusion, EL is a rare benign endobronchial tumor that can be safely resected by a bronchoscopic procedure. Surgery is recommanded when the distal lung parenchyma is damaged by an obstructive pneumonia or fibrosis.

\section{References}

1. Kamiyoshihara M, Sakata K, Otani Y, Kawashima O, Takahashi T, Morishita Y. Endobronchial lipoma accompained with primary lung cancer: report of a case. SurgToday. 2002;32:402-5.

2. Muraoka M, Oka T, Akamine S, Nagayasu T, Iseki M, Suyama N, et al. Endobronchial lipoma. Chest. 2003;123:293-6.

3. Jensen MS, Petersen AH. Bronchial lipoma: three cases and review of the literature. Scand J Thorac Cardiovasc Surg. 1970;4:131-4.

4. Schraufnagel DE, Morin JE, Wang NS. Endobronchial lipoma. Chest. 1979;75:97-9.

5. Politis J, Funahashi A, Gehlsen JA, DeCock D, Stengel BF, Choi H. Intrathoracic lipomas: report of three cases and review of the literature with the emphasis on endobronchial lipoma. $J$ Thorac Cardiovasc Surg. 1979;77:550-6.

\title{
A new type of diaphragmatic hernia: Anterolateral hernia
}

\author{
Jérôme Mouroux, MD, PhD, Daniel Pop, MD, Patrice Guiraudet, MD, Ricardo Giovanetti, MD, Jérôme Lauron, MD, \\ and Nicolas Venissac, MD, Nice, France
}

$\mathrm{H}$ eterogenous types of acquired hernias in the diaphragm have been described in the literature: the hiatal hernia through the esophageal foramen and the posterolateral hernia through the Henle costolumbar orifice or anterior foramen of Larrey-Morgagni hernia (retroxiphoid hernias). ${ }^{1,2}$ To our knowledge, no anterolateral hernia has been reported. We describe the case of a hernia between the eighth and ninth anterior costochondral insertion of the muscular fibers of the diaphragm.

From the Thoracic Surgery Department, Pasteur Hospital, Nice, France. Received for publication Sept 14, 2007; accepted for publication Dec 4, 2007.

Address for reprints: Daniel Pop, MD, Thoracic Surgery Department, Pasteur Hospital, Buiding H1, 30 Avenue de la Voie Romaine, 06002 Nice, France (E-mail: danielpopch@yahoo.com).

J Thorac Cardiovasc Surg 2008;135:955-6

$0022-5223 / \$ 34.00$

Copyright (C) 2008 by The American Association for Thoracic Surgery doi:10.1016/j.jtcvs.2007.12.001

\section{Clinical Summary}

A 76-year-old man had a medical history of diabetes mellitus, arterial hypertension, a bilateral inguinal hernia (operated), and a $2 / 3$ gastrectomy for gastric ulcer (50 years ago). In 1999, a chest xray showed an air-filled opacity in the left thoracic base. No further investigations were done. In September of 2005, the patient experienced a blocking respiration symptom in the left hemithorax, especially after meals and occasionally associated with vomiting. The chest $\mathrm{x}$-ray showed colic haustration at the left thoracic base. A gastroesophageal endoscopy showed no anomaly. The cardial sphincter was $40 \mathrm{~cm}$ from the incisor teeth, and the gastric stump and duodenal-gastric anastomosis were healthy. The barium esophagography showed a normal cardial region. The chest computed tomography scan demonstrated a colic ascent in the left thorax and the small intestine through an anterolateral hole of the diaphragm (Figure 1).

Surgery was performed via a low left posterolateral thoracotomy. We found the peritoneal sac containing the digestive loops (Figure 2). After clearly identifying the edges, we resected and closed the sac. These edges corresponded to the muscular fibers of the diaphragm inserted at the eighth and ninth chondrocostal cartilage. The hole measured $10 \mathrm{~cm}$ in the anteroposterior diameter, was located far from the retroxiphoid region, and ended at the central tendon. The closure was done with nonabsorbable sutures. The 